\title{
A influência de Rodrigo Costa da Rocha Loures na Presidência da FIEP
}

Dário José Costa Junior ${ }^{1}$ Lucas Coelho Goscinski²

- Enviado em 30/09/2017

- Aprovado em 08/12/2017

\section{INTRODUÇÃO}

Desde a sua criação em 1944, a Federação das Indústrias do Paraná se tornou parte importante na sociedade empresarial e na economia paranaense. Presente em diversas áreas, o sistema FIEP possui várias delimitações para atender a demanda industrial e buscar inovações e tecnologias para todos os setores atrelados a esse sistema. Grandes nomes empresariais e da política do Paraná, já ocuparam e ainda ocupam grandes cargos administrativos na entidade, e talvez um dos mais importantes nomes seja o de Rodrigo Costa da Rocha Loures, que ocupou o cargo de presidente da FIEP no período de 2003-2011.

Membro de uma das famílias de elite mais importantes da história do estado, Rodrigo impulsionou as indústrias do Paraná. Desde a fundação da sua empresa Nutrimental, desenvolveu diversas ações estratégicas e mercadológicas para auxiliar e consolidar as indústrias paranaenses no cenário político e econômico nacional. As pesquisas que seguirão adiante, avaliarão sua influência nesse aspecto, citando os diversos programas e eventos criados durante sua gestão, fazendo também uma análise biográfica da sua carreira empresarial, de seus feitos, envolvimentos em escândalos e relações políticas e familiares.

\section{FEDERAÇÃO DAS INDÚSTRIAS DO PARANÁ (FIEP).}

Em 1943, surgiu a iniciativa de criar uma entidade oficial para representar os empresários paranaenses. Logo, várias medidas foram tomadas para esta ideia sair do papel, e finalmente, em 18 de agosto de 1944, deu-se início à Federação das Indústrias do Estado do Paraná (FIEP). Teve como principal objetivo desenvolver os diversos setores industriais do Estado, pois a economia paranaense era fortemente representada pela agricultura, e as indústrias em geral se resumiam em extrativismo.

\footnotetext{
${ }^{1}$ Graduando do $2^{\circ}$ período em Engenharia de Controle e Automação pela Universidade Tecnológica Federal do Paraná. ${ }^{2}$ Graduando do $2^{\circ}$ período em Engenharia de Controle e Automação pela Universidade Tecnológica Federal do Paraná
} 
"Aos vinte e oito dias do mês de outubro, do ano de mil e novecentos e quarenta e três (1943), nesta Cidade de Curitiba, Capital do Estado do Paraná, na sede do Sindicato da Indústria do Mate, à rua Marechal Floriano Peixoto $n^{\circ} 134,2^{\circ}$ andar, reunidos os Delegados dos diversos Sindicatos das Indústrias do Estado do Paraná, e tendo assinado o livro de presença, foi feita pelo Dr. Álvaro de Albuquerque, Delegado do Ministério do Trabalho, uma exposição sobre a necessidade da sindicalização de todas as classes e conveniência da fundação de Federação; ainda as excepcionais vantagens que advirão ao Estado com a congregação de toda a força econômica de sua indústria numa só Federação...". Assim, começa a primeira ata referente à fundação da atual Federação das Indústrias do Estado do Paraná." ${ }^{3}$

\section{FUNÇÕES DA FEDERAÇÃO}

A FIEP elabora, executa e promove programas de melhoria de gestão, análise e orientação política e econômica, identificação de oportunidades de negócios, além de outras ações voltadas para o crescimento sustentável da indústria do Paraná. Tais ações da FIEP são pautadas nas necessidades do segmento industrial, com base nos cenários econômico, político e social, por isso, oferece: assessorias, consultorias e suporte em áreas vitais como linhas de crédito e financiamento, tributos e legislação, comércio exterior e meio ambiente. Também faz a interlocução com o poder público, atendimento jurídico e defesa dos interesses conjuntos, encontros de negócios, networking nacional e internacional, e desenvolvimento de programas de fortalecimento da base sindical. Em seis décadas de existência, a Federação das Indústrias do Estado do Paraná se consolidou como a maior entidade empresarial do Estado. Hoje, a instituição representa quase 30 mil empresas, filiadas a 96 sindicatos. ${ }^{4}$

\section{PRESIDENTES E SUPERINTENDES DA FIEP ${ }^{5}$}

- HEITOR STOCKLER DE FRANÇA: Nasceu em 05 de novembro de 1888, na cidade de Palmeira, interior do Paraná. É filho de Leandrina Marcondes Ribas Stockler de França e de João de Araújo França. Casou-se com Brasília Taborda Ribas de França com quem teve seis filhos. Se formou em Ciências Jurídicas e Sociais na

${ }_{3}$ Disponível em http://www.fiepr.org.br/centrodememoria//uploadAddress/Primeiros\%20Passos\%20FIEP[26893].pdf. Acesso em 03/11/2017.

4 Disponível em http://www.sistemafiep.org.br/. Acesso em 03/11/2017. http://www.sistemafiep.org.br/conheca/fiep-2-31682342082.shtml Acesso em 03/11/2017.

5 Relação dos presidentes e superintendentes que já passaram pela FIEP. Disponível em http://www.fiepr.org.br/centrodememoria/presidentes-fiep-1-14926-117715.shtml_Acesso em 07/11/2017. http://www.fiepr.org.br/centrodememoria/superintendentes--1-14926-117958.shtml. Acesso em 07/11/2017. 
Faculdade de Direito da Universidade do Paraná. França foi um grande comerciante e um dos fundadores da FIEP, a qual presidiu entre $1946-1958^{6}$.

- LYDIO PAULO BETTEGA: Nasceu em 18 de junho de 1904, em Piraquara, Paraná. Se formou em Economia e Finanças pelo Instituto Don Bosco, Buenos Aires, Argentina. Licenciou-se em Línguas Vivas, Filosofia Pura, Apologética, Psicologia, Literatura e História, pelo Instituto Pio Nono, PUC de Buenos Aires, Argentina. Foi o segundo presidente da FIEP, cargo que ocupou entre $1958-1968 .^{7}$

- MÁRIO DE MARI: Nasceu em 06 de setembro de 1922, em Curitiba. Formou-se em Engenharia Civil pela Universidade do Paraná, no ano de 1946. Foi o primeiro Diretor do Departamento de Urbanismo e Chefe da Divisão de Pavimentação de Curitiba. Esteve à frente do cargo de presidente da FIEP entre os anos de 1968 $-1974 .^{8}$

- ALTAVIR ZANIOLO: Nasceu em 6 de julho de 1922, em São José dos Pinhais, Paraná. Formou-se no ano de 1941 em técnico em Administração e Contador. Passou 12 anos no comando da FIEP, entre os anos de 1974 $-1986 .^{9}$

Zaniolo foi um grande empresário no setor madeireiro, além de ter atuado na agricultura, fábrica de plásticos e também no setor de bebidas (LOEFFLER, 2009, pg.164)

- JORGE ALOYSIO WEBER: Nasceu em 16 de março de 1928 em Passo Fundo (RS). Formou-se em Técnico em Contabilidade, além de realizar vários cursos na Área Administrativa, de Recursos Humanos e Sindicalismo, no Brasil e no Exterior. Durante o primeiro mandato do governo de Requião, Weber foi secretário de Estado da Indústria e Comércio do Paraná. Foi presidente da FIEP durantes os anos de $1986-1995 .^{10}$

- JOSÉ CARLOS GOMES CARVALHO: É natural de Santo Antônio da Platina (PR), nascido em 8 de junho de 1935. Carvalho é filho de José Domingos Marcondes Carvalho e de Josefina Gomes de Carvalho. Formou-se

\footnotetext{
6 "Poucos paranaenses têm na sua genealogia tão grande número de nomes ilustres quanto os descendentes de Heitor Stockler de França. As origens da família chegam a remontar a Martin Afonso de Souza". Biografia e texto de Tomás Barreiros. Disponível em http://tomasbarreiros.com.br/sem-categoria/serie-raizes-os-paranaenses-vi-heitor-stockler-de-franca-comerciante-industrial-epoeta/. Acesso em 25/11/2017.

7 Não encontramos a genealogia de Bettega, somente relatos de sua passagem pela presidência da FIEP. Disponível em http://www.fiepr.org.br/centrodememoria/lydio-paulo-bettega-1-14926-117721.shtml. Acesso em 25/11/2017.

8 Não encontramos a genealogia de Mari, somente relatos de sua passagem pela presidência da FIEP. Disponível em http://www.fiepr.org.br/centrodememoria/mario-de-mari-1-14926-117727.shtml. Acesso em 25/11/2017.

9 Não encontramos a genealogia de Zaniolo, há somente publicado sua vida empresarial. Disponível em: http://www.fiepr.org.br/centrodememoria/altavir-zaniolo-1-14926-117729.shtml._Acesso em 25/11/2017.

10 Não encontramos a genealogia de Weber, somente relatos de sua passagem pela presidência da FIEP. Disponível em http://www.fiepr.org.br/centrodememoria/jorge-aloysio-weber-1-14926-117731.shtml. Acesso em 25/11/2017.
} 
em ciências jurídicas e sociais pela Faculdade de Direito de Curitiba em 1959, foi durante muitos anos presidente do grupo Corujão. Na FIEP, esteve no comando entre os anos de 1995 - 2003. Morreu em 01/10/2003, quando se preparava para deixar o cargo na Federação. ${ }^{11}$

Como político, foi senador entre 1987 e 1995 e também vice-prefeito de Curitiba, assumindo várias vezes o cargo de prefeito no período entre 1993 e 1997. Também foi secretário de Estado da Indústria e Comércio entre 1987 e 1989 e secretário de Estado do Emprego e Relações do Trabalho entre 1999 e 2001..$^{12}$

Alguns meses após a sua morte, a nova diretoria da Fiep solicitou uma auditoria nas contas da instituição durante sua gestão, e foram constatadas várias irregularidades financeiras, entre as quais o desvio de cerca de 36 milhões de reais do Instituto Euvaldo Lodi (IEL), entidade mantida pelas federações das indústrias como organismo de integração entre empresas e escolas. Em virtude dessas irregularidades o Ministério Público do Paraná, em conjunto com outras entidades, inclusive a própria Fiep, entrou com uma ação civil pública de improbidade administrativa contra Carvalho e seus herdeiros. De acordo com a denúncia do Ministério Público, os recursos desviados correspondiam a contribuições parafiscais repassadas ao IEL pelo Sesi e pelo Senai entre 1996 e 2003. Em fevereiro de 2007 o juizado da 3a Vara da Fazenda Pública determinou o bloqueio em caráter liminar de seus bens, em consequência da ação movida pelo Ministério Público, que visava ao ressarcimento dos valores aos cofres públicos, visto que as contribuições parafiscais são consideradas verbas públicas. ${ }^{13}$

- RODRIGO COSTA DA ROCHA LOURES: Presidente entre $2003-2011 .^{14}$

- EDSON LUIZ CAMPAGNOLO: Nascido em 1959, em Francisco Beltrão, é casado com Sueli Roveda Campagnolo, com quem possui dois filhos. Não é membro de uma família tradicional do Paraná, pois começou sua trajetória ajudando a administrar uma pequena malharia montada por sua mãe na própria casa da família. Hoje continua atuando no ramo têxtil, tendo grande representatividade no setor. Na FIEP, foi eleito em 2011, e hoje está cumprindo seu segundo mandato como presidente. ${ }^{15}$

11 Disponível em http://www.fgv.br/cpdoc/acervo/dicionarios/verbete-biografico/carvalho-jose-carlos-gomes-de. Acesso em 25/11/2017.

12 Disponível em http://www.tribunapr.com.br/noticias/parana/presidente-da-fiep-morre-aos-68-anos/ Acesso em 25/11/2017.

13 Disponível em http://www.fgv.br/cpdoc/acervo/dicionarios/verbete-biografico/carvalho-jose-carlos-gomes-de. Acesso em $25 / 11 / 2017$.

${ }^{14}$ Nesse caso em especial a biografia será separada, sendo relatada na próxima página pois merece destaque.

15 Trajetória do atual presidente da FIEP disponível em http://memoriasparana.com.br/edson-luiz-campagnolo-2016-2/. Acesso em 25/11/2017. 
- SUPERINTENDENTES: dos três superintendentes que já passaram ou ainda estão na FIEP, Luiz Malucelli Neto, Arthur Carlos Peralta Neto ${ }^{16}$ e Ovaldir Nardin ${ }^{17}$, temos que dar destaque aos dois últimos citados, respectivamente, pois o período de exercício de tais inicia-se assim que Rocha Loures toma posse como presidente da Federação. Carlos Peralta Neto é Diretor Jurídico do Grupo Nutrimental S/A e Nardin é Diretor Financeiro do mesmo grupo ${ }^{18}$, que pertence ao então Presidente da FIEP na época. Por mérito ou não, o alto escalão da Federação durante muitos anos foi composto pelos gerenciadores do grupo Nutrimental, deixando claro o poder e influência que Rocha Loures possui no Paraná.

\section{QUEM É RODRIGO COSTA DA ROCHA LOURES}

Nasceu no dia 10 de julho de 1943, em Curitiba, Paraná. Formado em Administração de Empresas pela Fundação Getúlio Vargas, em São Paulo. Foi professor de Administração na Universidade Federal do Paraná. No ano de 1968, fundou a Nutrimental, indústria do segmento alimentício que detém a barra de cereais mais vendida no Brasil. ${ }^{19}$

Assumiu em outubro de 2003, a presidência do Sistema Federação das Indústrias do Estado do Paraná (FIEP). Foi novamente eleito em 2007, para um mandato que durou quatro anos. É vice-presidente da Confederação Nacional da Indústria (CNI), ex presidente do Conselho Temático Permanente de Política Industrial e Desenvolvimento Tecnológico da CNI - COPIN e presidente do Conselho Deliberativo do Instituto Brasileiro de Qualidade e Produtividade (IBQP). Loures integra o Conselho de Desenvolvimento Econômico e Social da Presidência da República e é titular do Conselho Nacional de Ciência e Tecnologia. O empresário também tem influência na sustentabilidade, pois é membro da Fundação Brasileira do Desenvolvimento Sustentável (FBDS), da World Business Academy (WBA) e do Instituto ETHOS de Responsabilidade Social. Integra o Conselho de Desenvolvimento Econômico e Social (CDES) da Presidência

\footnotetext{
16 Neto é formado em Direito pela Universidade Federal do Paraná - 1985, possui especialização em Direito Empresarial pela Pontifica Universidade Católica do Paraná - 2002. Disponível em http://www.fiepr.org.br/para-empresas/camara-dearbitragem/arbitro-arthur-carlos-peralta-neto--1-20704-248399.shtml. Acesso em 25/11/2017. Não encontramos mais informações sobre o empresário, bem como sua genealogia.

17 Formado em Ciências Econômicas pela Universidade Católica do Paraná. Disponível em https://www.linkedin.com/in/ovaldirnardin-30371834/. Acesso em 25/11/2017. Não encontramos mais informações sobre o empresário, bem como sua genealogia.

${ }^{18}$ Disponível em http://www.fiepr.org.br/para-empresas/camara-de-arbitragem/. Acesso em 11/11/2017.

19 Disponível em http://www.gazetadopovo.com.br/politica/republica/imperio-das-barrinhas-de-cereal-deu-projecao-a-rodrigorocha-loures-7q3uur01g22jfnlex15q11moj. Acesso em 25/11/2017.
} 
da República e o Conselho Diretor do Fundo Nacional de Desenvolvimento Científico e Tecnológico (FNDCT). ${ }^{20}$

\title{
PODER QUE ATRAVESSA SÉCULOS
}

Rocha Loures vem de uma família com mais de 300 anos de poder no Paraná, e ainda hoje é um dos maiores líderes empresariais do Estado (OLIVEIRA, 2007).

\begin{abstract}
Dos sete filhos do casal Antônio Ferreira da Rocha Loures e Joana Maria de Lima, a filha mais velha, Maria Francisca da Rocha é a ascendente do fundador da empresa Nutrimental (Rodrigo Costa Rocha Loures). Maria Francisca casou com o capitão João Carvalho de Assumpção. Tiveram quatro filhos, entre eles Gertrudes Maria da Assumpção que casou com Francisco Antônio Alves da Rocha. Gertrudes e Francisco tiveram doze filhos. Seu nono filho foi Jesuíno Alves da Rocha Loures, avô do fundador da Nutrimental. Jesuíno casou com Francisca Ferreira da Siqueira e tiveram nove filhos, entre eles João Alves da Rocha Loures (1900-1986), pai do fundador da Nutrimental. Em 21 de setembro de 1929 João Alves casou com Rachel Faria Affonso da Costa (19092006). Tiveram nove filhos. O sexto filho é Rodrigo Costa da Rocha Loures, fundador da Nutrimental. Rodrigo Costa nasceu em Curitiba a 10 de julho de 1943. Aos cinco dias de janeiro de 1966 casou com Vera Lilia Santos, nascida em Curitiba a 3 de maio de 1946. Rodrigo Costa e Vera tiveram três filhos. O mais velho é Rodrigo Santos da Rocha Loures, nascido em Curitiba em 13 de novembro de 1966. Rodrigo Santos é casado com Karin Peter e pai de dois filhos - Mayra e Dyego (PIERUCCINI, 1995; TEIXEIRA, 2009). Podemos perceber que a genealogia da família Rocha Loures é marcada pelo lado paterno como descendentes dos clãs patriarcas fundadores de Curitiba: Carrasco do Reis e Mateus Leme que constituíam a elite de sua época e cujos descendentes seriam figuras públicas de destaque na sociedade paranaense. Pelo lado materno, Rachel Faria era neta do Presidente Faria (que foi duas vezes presidente da Província do Paraná) e descendente de Lourenço Pinto de Sá Ribas (deputado pela 5a Comarca na Assembleia Provincial Paulista e presidente da Câmara de Curitiba). Era tataraneta de Lourenço Ribeiro de Andrade (capitão-mor de Curitiba) e filha de Didio Costa (oficial da Marinha de Guerra Brasileira, intelectual renomado, deputado estadual no Congresso Legislativo Paranaense e prefeito de Paranaguá destituído pela Revolução de 30$).{ }^{21}$
\end{abstract}

O empresário possui dois filhos, sendo o mais velho Rodrigo Santos Rocha Loures ${ }^{22}$, que entrou na política diretamente como Deputado Federal, cargo que ocupa atualmente. Ele é investigado pela operação lava-jato e protagonista de um dos maiores escândalos de corrupção no ano de 2017, envolvendo

\footnotetext{
20 Disponível em http://www.fiesp.com.br/noticias/perfil-rodrigo-costa-da-rocha-loures-presidente-do-conic-da-fiesp/ Acesso em 11/11/2017. http://www.fiepr.org.br/centrodememoria/rodrigo-costa-da-rocha-loures-1-14926-117738.shtml Acesso em $10 / 11 / 2017$.

21 Trecho elaborado por Ana Crhistina Vanali e Katiano Miguel Cruz, disponível em: http://revistas.ufpr.br/nep/article/view/46979/28173. Acesso em 11/11/2017.

22 Loures (filho), mais conhecido como Rodriguinho, nasceu em 13/11/1966 em Curitiba. É filho de Rodrigo da Costa Loures e Vera Lilia Santos da Rocha Loures. É formado em Administração pela Fundação Getúlio Vargas. Assim que obteve seu diploma, já iniciou seus trabalhos na Nutrimental.
} 
diretamente o presidente da República Michel Temer. Loures (filho), conhecido como Rodriguinho, foi flagrado recebendo uma mala com cerca de 500 mil reais, em nome de Temer, a qual ele permaneceria recebendo, segundo Joesley Batista, dono da JBS e autor dos pagamentos, toda semana durante os próximos 20 anos. $^{23}$

Em 2010, foi vice de Osmar Dias, irmão de Álvaro Dias, na disputa pelo Governo do Estado, acabaram derrotados pelo então Prefeito de Curitiba Beto Richa, que permanece até hoje como Governador, atualmente no segundo mandato. Sua campanha em 2014 para Deputado Federal recebeu doações de Michel Temer e João Dória, atual prefeito de São Paulo. Sua relação com o Presidente da República é antiga, em 2011, foi designado para ser chefe de gabinete de Temer, que ainda era vicepresidente. ${ }^{24}$

\section{ROCHA LOURES NO COMANDO DA FIEP}

Em 2003, Rocha Loures contou com o apoio de Requião na sua eleição para Presidente da FIEP. A relação entre o empresário e o então governador do Estado do Paraná merece destaque, pois além de diretamente manterem apoio um ao outro, suas famílias também se organizavam em conjunto, além do mais, a empresa Nutrimental, de Loures, foi investigada por fraudes na distribuição de merenda escolar, durante o governo de Requião. No conjunto familiar, o filho de Rocha Loures, Rodrigo Santos Rocha Loures, foi chefe de gabinete de Requião em 2003/4 e, eleito deputado federal pelo PMDB em 2006, teve como chefe de gabinete o filho de Roberto Requião, Maurício Thadeu de Mello e Silva, mais conhecido como Requião Filho (OLIVEIRA, 2007). “Eu comecei minha caminhada ao lado de Requião”, enaltecia Rocha Loures. ${ }^{25}$ Porém, após os escândalos da JBS, Requião, em sua conta no Twitter, chega até a elogiar Loures, contudo, critica sua escolha de se aliar a Temer. "Rodrigo Rocha Loures, idealista, meu amigo. O que fizeram de você, Rodrigo Rocha Loures? Vejo tudo com indignação e muita tristeza. CANALHAS!"26

23 Disponível em https://www.brasildefato.com.br/2017/05/19/rocha-loures-a-familia-tradicional-paranaense-no-seio-dasdenuncias-contra-temer/. Acesso em 25/11/2017.

${ }^{24}$ Disponível em http://www.gazetadopovo.com.br/politica/parana/de-requiao-a-osmar-dias-o-historico-das-ligacoes-politicas-derocha-loures-5kjyjyon9134a22i4wwu7cc41. Acesso em 12/11/2017.

${ }^{25} \mathrm{Em} \mathrm{2014}$, o deputado aparece ao lado do então Senador Roberto Requião, apoiando sua candidatura para o governo do Estado. Disponível em: https://www.youtube.com/watch?v=gCXkiut0mVg Acesso em 12/11/2017.

${ }^{26}$ Disponível em: https://twitter.com/requiaopmdb Acesso em 12/11/2017. 
A trajetória de Rocha Loures (pai) na FIEP não foi apenas resumida a apoios a políticos, ele também inovou e deu grandes contribuições à indústria paranaense. Mostraremos abaixo resumidamente alguns de seus feitos.

- Rede de Tecnologia do Paraná - RETEC;

- Rede de Participação Política do Empresariado;

- Cartão Sesi. Implantação em 2006.

- Congresso da Indústria Paranaense (2004, 2006, 2009);

- Congresso de Inovação na Indústria;

- Apoio à micro e pequenas empresas;

- Movimento Nós Podemos Paraná;

- Investimentos em ampliação e modernização de Centros Integrados;

- Coleção Inova;

- Movimento Global Fórum. ${ }^{27}$

Nos quatros primeiros anos de mandato, já obteve grandes resultados, dos quais ele tem muito orgulho de comentar:

...multiplicamos os investimentos produtivos em 15 vezes, em relação à gestão anterior. Já foram aplicados em obras para modernização e ampliação da infraestrutura $\mathrm{R} \$ 70$ milhões. As matrículas de cursos profissionalizantes e de educação do Sesi e do Senai aumentaram até cinco vezes. O Sistema FIEP ganhou visibilidade, espaço e projeção nacional. Isso só foi possível graças ao resgate ético, à profissionalização, a uma gestão participativa e ao restabelecimento da independência e autonomia da federação. Tivemos uma grande interiorização do Sistema. Os principais projetos inovadores foram a Universidade da Indústria (Unindus), para capacitação e aperfeiçoamento de executivos e empresários; o Colégio Sesi de Ensino Médio, que une o currículo formal à educação profissional e usa metodologia inovadora que valoriza empreendedorismo e criatividade; o Cartão Sesi, que retoma a prestação de serviços odontológicos para o trabalhador da indústria; as Agências de Desenvolvimento Regional; os 20 Arranjos Produtivos Locais, constituídos em todas as regiões do Estado e também a elaboração de uma proposta de Política Industrial e Desenvolvimento Tecnológico à altura de nosso Estado. ${ }^{28}$

Nos oitos anos que comandou a instituição obteve incríveis resultados, Loures foi inegavelmente um ótimo presidente frente a FIEP Mesmo se envolvendo em alguns escândalos de desvio de dinheiro, ele agigantou a Federação, só em estruturas para novas unidades ou reforma e modernização, a FIEP aplicou R\$225 milhões, todos esses investimentos reforçaram a presença da Federação, Sesi, Senai e IEL

27 Disponivel em: http://www.fiepr.org.br/centrodememoria/rodrigo-costa-da-rocha-loures-1-14926-117738.shtml Acesso em $12 / 11 / 2017$.

28 Entrevista cedida por Rodrigo Costa da Rocha Loures à Folha CRCPR logo após ser reeleito na FIEP. Disponível em https://crcpr.jusbrasil.com.br/noticias/2903163/rocha-loures-fala-sobre-seu-trabalho-na-federacao-das-industrias-do-estado-do-parana-fiep. Acesso em 12/11/2017. 
em todo o Estado, atendendo e cumprindo as responsabilidades que as indústrias necessitavam no Paraná. ${ }^{29}$

A educação foi priorizada para que o Estado tivesse um desenvolvimento sustentável, os investimentos possibilitaram também uma grande ampliação no número de vagas, com recordes de números, em serviços de educação e formação profissional.

Mas como a história nem sempre é escrita apenas com base em méritos, temos que também falar sobre os desvios que aconteceram na gestão de Loures segundo apuração do jornal Tribuna do Paraná:

Sobre as supostas irregularidades cometidas na atual gestão, entre elas despesas amparadas em documentos inidôneos; despesas que teriam beneficiado funcionários das entidades sem comprovação da prestação de serviços; repasse de R\$ 265 mil e R\$ 561 mil ao Instituto Paraná de Desenvolvimento (IPR), presidido por Rodrigo da Rocha Loures, sem qualquer comprovação de despesas; ressarcimento de despesas pessoais da filha de Rodrigo Rocha Loures, Larissa, tais como faturas telefônicas, restaurante, táxi; diversos pagamentos à empresa LWL Comunicações, de propriedade de Luiz Henrique Weber e Luciana Rocha Loures, sobrinha de Rodrigo; despesas com viagens para Cleveland para Luciana, sem comprovação de despesas ou justificativas; pagamento de passagens aéreas com destino ao Canadá para Dídio Costa Rocha Loures, irmão de Rodrigo, entre outras, o TCU autorizou a audiência de Rodrigo Rocha Loures a respeito; de Marcos Müeller Schlemm, diretor-superintendente do Sesi-PR; Ubiratan de Lara, ex-diretor-regional do Senai-PR; Carlos Sérgio Asinelli, diretor-regional do Senai-PR; Helena Gid Abage, exdiretora-superintendente-adjunta do IEL/PR e Gina Gulineli Paladino, diretora-executiva do IEL/PR. Todos eles poderão apresentar justificativas para as supostas irregularidades. ${ }^{30}$

Além deste caso, loures esteve envolvido em outro esquema, porém não sendo diretamente ligado a FIEP, e sim à sua empresa Nutrimental, pois como já citado acima, durante o governo de Requião, Gilda Poli da Rocha Loures era Secretária da Educação do Estado, e a principal fonte de renda da empresa vinha da distribuição de merenda às escolas do Paraná, essa 'coincidência' gerou um processo no TCU (OLIVEIRA, 2007). ${ }^{31}$

Por fim, apontamos que a empresa Nutrimental não tem relação com desvios de dinheiro ou corrupção, contudo, deixamos aqui um trecho do artigo de CORONA, (2013), pesquisadora da Universidade Tecnológica Federal do Paraná:

A produção mais intensiva para o mercado foi acompanhada de forte uso de agroquímicos, responsável por uma importante degradação do ambiente e da saúde de

\footnotetext{
29 Disponível em https://www.jornaldooeste.com.br/noticia/rocha-loures-deixa-presidencia-da-fiep-com-legado-de-grandestransformacoes. Acesso em 26/11/2017

30 Disponível em http://www.tribunapr.com.br/noticias/economia/tcu-determina-devolucao-de-r-36-milhoes-ao-sesisenai/. Acesso em 12/11/2017. Não encontramos informações atualizadas deste caso, nada foi divulgado.
}

${ }^{31}$ Não encontramos dados atualizados deste processo, nem mesmo o resultado. 
agricultores, segundo depoimentos dos entrevistados, como informou o entrevistado no. 8. Disse ele que nas décadas de $80 / 90$, sua família produziu grande quantidade de legumes para a uma grande empresa, inclusive ganhou prêmios de produtividade, mas ele teve duas fortes intoxicações por agrotóxicos porque os técnicos da empresa exigiam altas doses desses produtos para garantir a "qualidade". Essas intoxicações são responsáveis pelos graves problemas de saúde que ele tem atualmente e que o impedem de trabalhar, o que o faz apenas cultivar os vinhedos e a horta caseira de forma orgânica. Diz ele que "o cheiro de agrotóxico nas verduras que iam para a Nutrimental chegava a dar enjoo e desmaio de cheirar" e complementa "e era pra sopinha dos nenês.

\section{CONSIDERAÇÕES FINAIS}

As articulações de nomes importantes no poder de diversos cargos públicos, apoiados por famílias de elites dominantes é algo intrínseco na cultura brasileira. As gerações mudam, mas tais manobras também se adaptam de acordo com os interesses das pessoas envolvidas. Apesar dos supostos escândalos de corrupção, nomes importantes tornaram-se essenciais no desenvolvimento do estado do Paraná. Rodrigo Loures fez parte da história da FIEP, deixando um legado de melhorias para o desenvolvimento econômico e sustentável do Estado, em um dos discursos de despedida, após a posse do presidente sucessor ele afirma:

O que faz a história não é o presidente, é a soma da contribuição de milhares de profissionais.", afirma Rocha Loures. "O que eu posso me orgulhar é que nesse período em que fui presidente pude proporcionar um ambiente onde todos os nossos colaboradores, cada um no seu espaço, pôde desenvolver na plenitude a sua capacidade profissional", finaliza. ${ }^{32}$

A família Rocha Loures é um dos maiores exemplos de como se manter no poder durante séculos, aliando o prestígio do nome quando esteve na crise, com o poder econômico em tempos de bons rendimentos e hoje, mais do que nunca, o poder político que abre portas para se manter no poder do Estado durante muito mais tempo.

...nepotismo, clientelismo e diferentes artifícios são utilizados para as finalidades e resultados das redes políticas, que operam muitas vezes nos limites da legalidade e, por vezes, na ilegalidade. Redes políticas são de difícil visualização para o próprio ministério público, também passível de ser colonizado por redes políticas específicas. Podemos pesquisar em públicos diferentes redes políticas envolvendo parentes, amigos e assessores conectados em esquemas de poder. As redes mudam e transformam-se conforme as alterações da conjuntura e dos governantes. Apresentam múltiplos e diferentes esquemas para distintos governos e atores (OLIVEIRA, 2007).

\footnotetext{
${ }^{32}$ Discurso de Rocha Loures após deixar presidência da FIEP. Disponível em: www.jornaldooeste.com.br/noticia/rocha-loures-deixapresidencia-da-fiep-com-legado-de-grandes-transformacoes. Acesso em 12/11/2017.
} 
O interesse empresarial na política brasileira é gigantesco, o próprio Rocha Loures afirma em um artigo especial para um blog: "Os empresários são os maiores geradores de emprego, renda e tributos. Mas seu papel não se limita a empreender e gerar riqueza; vai muito além. É preciso assumir bandeiras como a do fortalecimento da sociedade e o saneamento da política pública. ${ }^{33}$ Loures tentou ingressar diretamente na política em 2012, ano em que disputou as eleições para prefeito de São José dos Pinhais, porém acabou ficando em segundo lugar com $26,51 \%$ dos votos. Era apontado como fortíssimo candidato nas próximas eleições, porém acabou não disputando. ${ }^{34}$

Temos então que, sendo influência direta como a própria participação da pessoa em questão, ou através de aliados políticos de outras pessoas influentes, tais sobrenomes importantes circulam e provavelmente continuarão circulando em cargos de alto escalão, tanto político quanto empresarial, não somente no estado do Paraná, mas no país inteiro durante muito tempo, quem sabe, por mais 300 anos, se nada mudar.

\section{REFERÊNCIAS}

LOEFFLER, Walli (2009). Aspectos da Indústria paranaense: 1930-1970. São Paulo, Teses USP, janeiro de 2009. Disponível em http://www.teses.usp.br/teses/disponiveis/8/8137/tde-06082009173130/publico/WALLI_LOEFFLER.pdf. Acesso em 25/11/2017.

OLIVEIRA, Ricardo Costa de (2007). Famílias, poder e riqueza: redes políticas no Paraná em 2007. IN: Sociologias, N.18. Porto Alegre, Julho/Dezembro. Disponível em http://www.scielo.br/pdf/soc/n18/n18a08. Acesso em 03/11/2017.

VANALI, Ana Crhistina, CRUZ Katiano Miguel (2015). Um exemplo de "old Money" no Paraná: A família Rocha Loures. Curitiba, Revista NEP (Núcleo de Estudos Paranaenses) v.2, n2, p.1-26, maio 2016. Disponível em http://revistas.ufpr.br/nep/article/view/46979/28173. Acesso em 11/11/2017.

CORONA, Hieda Maria Pagliosa (2013). O desenvolvimento rural e a agricultura familiar na RMC: da modernização à alternatividade à crise socioambiental. Toledo, Informe Gepec, v. 17, n. 1, p. 34-49,

33 Rodrigo Costa da Rocha Loures afirma que empresários devem atuar mais no cenário político. Disponível em www.esmaelmorais.com.br/2014/03/rodrigo-rocha-loures-empresarios-tem-que-atuar-mais-na-politica-e-nas-eleicoes/ Acesso em $12 / 11 / 2017$.

${ }^{34}$ Apurações dos votos das eleições de 2012 disponível em: http://g1.globo.com/pr/parana/apuracao/sao-jose-dos-pinhais.html. Acesso em 12/11/2017. 
jan./jun. 2013. Disponível em e-revista.unioeste.br/index.php/gepec/article/ download/5635/7123 Acesso em 12/11/2017.

\section{Notícias na internet}

http://justificando.cartacapital.com.br/2017/06/05/empresa-de-rocha-loures-apoiou-10-medidas-contracorrupcao/ Acesso em 12/11/2017.

https://noticias.uol.com.br/politica/ultimas-noticias/2017/07/01/pf-solta-ex-deputado-rocha-louresflagrado-com-mala-de-dinheiro.htm Acesso em 12/11/2017.

http://paranaportal.uol.com.br/colunas-sintonia-fina/ligada-ao-poder-familia-rocha-loures-sai-de-cenacom-prisao-de-rodriguinho/ Acesso em 12/11/2017. 